\section{ECONOMICS}

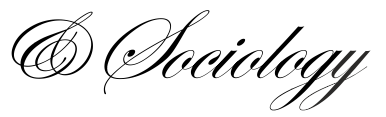

Domi, S., Keco, R., Capelleras, J.-L., \& Mehmeti, G. (2019). Effects of innovativeness and innovation behavior on tourism SMEs performance: The case of Albania. Economics and Sociology, 12(3), 67-85. doi:10.14254/2071789X.2019/12-3/5

\title{
EFFECTS OF INNOVATIVENESS AND INNOVATION BEHAVIOR ON TOURISM SMES PERFORMANCE: THE CASE OF ALBANIA
}

\author{
Shpresim Domi, \\ Agricultural University of Tirana, \\ Tirana, Albania \\ E-mail:shdomi@ubt.edu.al \\ Remzi Keco, \\ Agricultural University of Tirana, \\ Tirana, Albania \\ E-mail:rkeco@ubt.edu.al \\ Joan-Lluís Capelleras, \\ Universitat Autonoma de \\ Barcelona, \\ Barcelona, Spain \\ E-mail: \\ JoanLluis.Capelleras@uab.cat \\ Gentjan Mehmeti, \\ Agricultural University of Tirana, \\ Tirana, Albania \\ E-mail:gmebmeti@ubt.edu.al \\ Received: March, 2019 \\ 1st Revision: May, 2019 \\ Accepted: September, 2019
}

DOI: $10.14254 / 2071-$

789X.2019/12-3/5

JEL Classification: L25, O31, Z3
ABSTRACT. Though SMEs play a crucial role in countries' economic development, some of them succeed and others fail during their life cycle. In this regard, managers/owners continually have to identify the most significant factors that influence performance management. In addition, this is crucial for developing countries such as Albania, wherein such studies are lacking, furthermore, tourism sector is experiencing very fast development. Therefore, the purpose of this study is to empirically investigate the interplay of innovativeness, innovation behavior and SMEs' performance indicators. Exploiting face-to-face techniques, data for 211 valid cases have been gathered from Albanian tourism SMEs. By using SEM statistical methodology, the results indicate that innovativeness significantly affects innovation behavior. While innovativeness does not affect SMEs performance directly, its significant effects are indirect, through the mediation role of innovation behavior. Regarding innovation behavior, the results indicate that the more tourism's SMEs innovate in terms of ICT, cooperation (associations, networks etc.), the more their performance will positively increase. Operationalization of the vague term of innovation is a contribution to the literature. Finally, other theoretical and managerial contributions of this study are discussed.

Keywords: firm performance, innovativeness, innovation behavior, Albania

\section{Introduction}

Due to fierce competition, globalization and technology advancements along the last decades, the need to innovate is considered imperative (Tajeddini \& Trueman, 2008). In this context Ivanová \& Čepel (2018) state that "a key factor of the states' increasing competitiveness is assumed to be the innovation performance of enterprises, which is projected through innovative business processes into the innovation performance of the economy as a whole“. 
Within today's economy, where consumer preferences rapidly change, firms seek to deliver services and products in a cost-effective way so that to increase own profitability (Chen et al., 2009; Rajnoha \& Lorincová, 2015).

Innovation is a complex and wide concept. There are significant unresolved differences in opinions on how to measure it. Baregheh et al. (2009) pointed out that innovation is a multidisciplinary concept and different disciplines view innovation differently. Nevertheless, this paper operationalizes innovation in terms of innovativeness which refers to SME's culture to innovate, and innovation behaviour which is defined as the number of innovations practically implemented. To this, innovativeness is distinguished from innovation behavior as an organization's orientation towards innovation (e.g., Tajeddini, 2010; Grissemann et al., 2013), while innovation behavior is a quantity of new products and services that the firm actually introduces (e.g., Orfila-Sintes et al., 2005; Grissemann et al., 2013). Therefore, this study aims to investigate interactions of innovativeness, innovation behavior and SMEs performance indicators.

Significance of this study is multifold. First, innovation in tourism is an understudied area (Chan et al., 1998; Rodgers, 2007) and still relies on explorative and qualitative cases to a significant extent (Hjalager, 2010). Second, even though the performance implications of innovation in SMEs have attracted considerable interest among academics and practitioners (Rosenbusch et al., 2013), empirical research on this relationship has been showing controversial results and mixed findings (Rosenbusch et al., 2013). Thus, there are several studies which have concluded that innovation does not influence firm performance (Birley \& Westhead, 1990; Heunks, 1998), or find negative implications (e.g., Vermeulen et al., 2005). In contrast, DeCarolis \& Deeds (1999) and Li \& Atuahene-Gima (2001) report positive effects. As a result, these controversial results urge us for further investigation. Third, while interactions of these indicators are empirically investigated within economies with a well consolidated tourism development such as Austria, Germany, Italy and Switzerland (Grissemann et al., 2013), there is lack of research on this issue in a small and developing country like Albania, with an early stage of tourism development. However, it is imperative investigating issues that are directly related to tourism sector in developing countries such as Albania. Indeed, tourism is a crucial contributor to the economies of developing countries (Jones \& Haven-Tang, 2005). In Albania in particular tourism is one of the sectors with the greatest potential for overall socioeconomic development. To this, WTTC (2018) shows that direct contribution of travel and tourism to GDP accounts for $8.5 \%$ and generating $7.7 \%$ of the total employment $(93,500$ jobs $)$. Fourth, to examine the interplay effects of innovativeness, innovation behavior and performance indicators, this study has targeted Albanian tourism SMEs. This is crucial due to the fact that SMEs constitute $100 \%$ of the Albanian tourism sector. Although tourism SMEs are significantly contributing to socioeconomic development of the country, on the other side, several challenges such as short life span, informality, underdeveloped infrastructure, seasonality and inadequately educated workforce are assumed to hinder SMEs innovativeness and performance. However, this is an intriguing assumption to be deeply investigated.

The paper continues with the literature review section by theoretically arguing on direct and indirect relationships between innovativeness, innovation behavior and SMEs performance. The hypotheses to be tested are proposed. Along the methodological approach section, we discuss data collection and the sample, respondents' profiles, variables and measures, and the measurement model. Within the section Results structural equation modelling (SEM) methodology and the results of hypothesis testing are presented. The last section provides insights into the described relationships, some limitations of the study and future lines for research are also outlined. 


\section{Literature review}

Scholars perceive differently the concept of innovation. Several studies tackle innovation in terms of technological/technical innovation and organizational/administrative innovation (Daft, 1978; OECD, 1997, 2005; Orfila-Sintes et al., 2005). Despite these measures, current studies in the tourism sector measure innovation in terms of innovation behavioral (e.g., Orfila-Sintes et al., 2005; Grissemann et al., 2013; Domi, 2018) and innovativeness (e.g., Hurley \& Hult, 1998; Tajeddini, 2010; Grissemann et al., 2013; Domi, 2018). Innovativeness is related to the organization's attitude and the innovation behavior is related to an organization's behavior in terms of innovation. Some recent research in the tourism industry has called for more research that considers both the attitudinal and behavioral dimensions of innovation, namely innovativeness and innovation behavior (Grisseman et al., 2013; Sandvik et al., 2014).

\subsection{Innovativeness and SMEs performance}

Research on innovativeness has steadily expanded since Hurley and Hult (1998) considered it as one of the most important determinants of competitive advantage. Innovativeness is argued as an important strategic orientation for firms to achieve long-term success (Noble et al., 2002; Chen et al., 2009), significant effect on venture performance (e.g. Baum, 1995; Rauch \& Frese, 2000) and growth (Brännback, 1999). Zaltman et al. (1973), Hurley \& Hult (1988) and Hult et al. (2004) suggested that innovativeness is the initiation process of innovation which in turn represents the notion of openness to new ideas. Van de Ven (1986) considers innovativeness as the organization's culture to recognize the need for new ideas and actions. Grissemann et al. (2013) considered innovativeness as an "attitudinal dimension" of innovation. As a result, this study considered innovativeness as the attitude, values and beliefs and being open-mind by individuals and or firms to the change.

Within tourism SMEs context, innovativeness can take various forms, such as developing appropriate strategies, encouraging employees to come up with creative ideas, or simply being open toward the change (Tajeddini, 2010).

There are relevant and comprehensive studies that empirically show the influence of innovativeness on firm performance (see e.g. Grissemann et al., 2013; Tsai \& Yang, 2013; Tajeddini, 2010; Tajeddini \& Trueman, 2012; Domi, 2018). Hult et al. (2004), Tsai \& Yang (2013) in their empirical findings confirmed innovativeness as a crucial factor to enhance firm performance. Tajeddini \& Trueman (2012) concluded that if managers and employees are innovative or open to new ideas they are more likely to enhance firm performance in tourism sector. Although these positive relationships, on the other side, several other studies have found that innovativeness has no direct effects on firm performance (see e.g., Terziovski, 2010; Grissemann et al., 2013). As a result, as Tsai \& Yang (2013) have argued, even that innovativeness is assumed to enhance performance, the empirical researches have not yet achieved a consensus on that. In addition, studies on innovativeness-firm performance relationship, are still in its infancy (Tajeddini, 2010). In this line, the lack of sufficient empirical results to support the positive relationship between innovativeness and SMEs performance reinforces the need to replicate such studies to a new sample for a developing country such as Albania. This discussion leads us to the following hypothesis:

H1: Innovativeness has a positive effect on tourism SMEs' performance in Albania. 


\subsection{Innovativeness and innovation behavior}

Grissemann et al. (2013) argued that, a certain degree of innovativeness is necessary to encourage innovation behavior. In this way, we assume that the higher is the attitude, culture and being open-mind to innovate the more the innovation will take place into the SMEs. SMEs with a strong orientation toward innovation are more capable to practically provide innovative offerings (Rosenbusch, 2013). As a result, innovativeness reinforces innovation behaviors and stimulates innovative behaviors that may yield new products, services, or processes (Hurley \& Hult, 1998). Therefore, based on these arguments we propose that:

$\mathrm{H} 2$ : Innovativeness has positive effects on innovation behavior in Albania.

\subsection{Innovation behavior and SMEs performance}

Damanpour \& Wischnevsky (2006) described innovation behavior as the development and use of new product/service or method of operation. Innovation behavior is understood as the extent to which innovations are actually implemented within various areas of the firm (Orfila-Sintes et al., 2005). Kleysen \& Street (2001, p. 285) defined innovation behavior as "...all individual actions directed at the generation, introduction and or application of beneficial novelty at any organizational level". Additionally, innovation behavior also tracks whether an individual adopts innovations before others. Within tourism SMEs context, innovation behavior includes a wide range of factors such as establishing efficient registration and check-in/out systems, choosing outstanding architectural designs, or providing memorable experiences (Gilmore \& Pine, 2002).

Orfila-Sintes \& Mattsson (2009) argue that SMEs must consider the appropriate factors that successfully promote service innovations behaviors, and furthermore, those types of innovations that ensure efficiency, improve the service provided which respond to the customers' needs and wants. As Orfila-Sintes et al. (2005) and Grissemann et al. (2013), this study refers to the innovation behavior as the number innovations that are practically implemented within various areas of the tourism SMEs and are internally and externally oriented with their effects.

Literature in tourism finds innovation as a very important determinant that affects firm performance. Ottenbacher et al. (2006) identified a positive link between innovation behavior and hotels performance in terms of reputation. Grissemann et al. (2013) concluded that innovation behavior enhances financial performance, customer retention, increase efficiency, and reinforces the competitiveness position.

Orfila-Sintes \& Mattsson (2009) argue that a few studies have attempted to investigate innovation behavior in the tourism sector. Furthermore, this concept was elaborated only in hotel industry (see e.g. Grissemann et al., 2013; Orfila-Sintes \& Mattsson, 2009). Thus, considering innovation behavior within more broad industries of tourism such as hotels, tourism agencies and restaurants will provide more representative results for the tourism sector as a whole. This argument is in the framework of the need to better generalize the results of the study. Consequently, extending the study of innovation in a more representative target group will bring new insight into innovation studies in tourism. Based on the above arguments we propose the following hypothesis:

H3: Innovation behavior has a positive effect on tourism SMEs performance in Albania.

While Matsuo (2006) noted that a creative work environment encourages innovation behavior in businesses, Chen et al. (2009) concluded that businesses should practically innovate in terms of services in order to improve their business performance. SMEs should 
create a positive climate toward innovativeness, to encourage employees to think outside the box and accepting their new creative ideas, in order to come up with new products/services and as result achieving profit and sales goals. Hence, we argue that only having a positive attitude toward innovation will not boost profits or keep customers. Firms should go a step further and consider the need to implement innovation in order to enhance performance. By injecting the attitudinal dimension of innovation to the managers and employees, it is expected to foster the innovation implementation, which in turn will enhance performance. In this vein, Grissemann et al. (2013) found a positive effect of innovativeness on financial performance and this effect was mediated by innovation behavior.

While there are several studies elaborating the effects of innovativeness on innovation behavior (e.g. Grissemann et al., 2013; Matsuo, 2006) and the effects of innovation behavior on business performance (e.g., Storey \& Easingwood, 1998; Ottenbacher \& Gnoth, 2005; Ottenbacher et al., 2006; Chen et al., 2009; Grissemann et al., 2013), on the other hand, there is a scant of studies investigating the effects of innovativeness on business performance mediated by innovation behavior. Thus, according to the above discussions, we propose the following hypothesis.

H4: The effect of innovativeness on SMEs performance is mediated by innovation behavior in Albania.

\subsection{The Albanian tourism sector and the need for innovation at SMES}

While interplay of the attitudinal and behavioral dimensions of innovation and firm performance, are empirically investigated at mostly in Western Europe, the United States and Australia (see e.g., Agarwal et al., 2003; Tajeddini \& Trueman, 2012; Grissemann et al., 2013; Lee et al., 2016), on the other side, there is a lack of research on this issue in a small and developing country like Albania.

Albanian tourism sector has a short life-span. The first tourism law and tourism strategy development was compiled only at the beginning of ' 90 s (after the falling of the communism system) which were not fully reflected on a real industry, due to a high informality, too few tourism firms, not consolidated institutions related to the tourism policymaking, vagueness on private property issues etc. The real impact of tourism was only at the beginning of 2000s, when started to arrive a reasonable number of international visitors (WTTC, 2018). However there are still several concerns that the sector is dealing with. To this, tourism sector in Albania yet it suffers by a high level of informality (MTM, 2014), pronounced seasonality, high turnover of employee etc., which directly and indirectly influence the SMEs' culture and implementation of innovation. For example, high turnover of employee and seasonality nature of the sector, restricts possibility of the SMEs to innovate. This restriction is reflected even at the Albania rank in terms of ICT use for biz-to-biz transactions (112th out of 136) and Internet use for biz-to-consumer transactions (116th out of 136) (WEF, 2015).

Recently Albania is increasingly gaining an international reputation as a tourism destination due to its wealth in mountains, lakes, rivers and forests, varied wildlife and climates, complemented by a diverse menu of cultural heritage (Hall, 2000). Due to its geographic position within the European continent, which attracts roughly $51 \%$ of world international visitors flow (WTTC, 2018), constitute a potential opportunity for the development of the tourism industries. Referring to the World Bank (2019), along the period of 2007-2017, international tourist arrivals are increased up to 4.7 times (i.e., from 1,062,000 to $4,643,000$ ). This exponential increase is higher than other countries of the Balkan region such as Montenegro (1.9 times), Serbia (2.1 times), and some of the EU countries such as Italy (1.33 times), Austria (1.42 times) and Greece (1.68 times), within the same period. In 
addition, Albanian government has been directly engaged in promoting its country as a tourism destination through commercial advertisement on international TV channels (e.g., BBC), social media and participation in international fairs (e.g., Expo Milano, ITB Berlin etc.). Indeed, Albanian tourism is better ranked than other countries of the Balkan region (e.g., Serbia and Bosnia \& Herzegovina) in the 'Government prioritization of travel and tourism industry' index of the WEF (2015). However, while this strategy of tourism development helps to keep visitors in the short-terms, on the other side, providing high quality services helps to keep them in the long-terms. In this framework, (Mok and Armstrong, 1998) stated that aggressive advertising and promotions only attract more visitors to experience poor service and convince them to not repeat their visit in the future. To this, they suggest to be aware on this respect and to provide high quality service which in turn will determine the success. As a result, all stakeholders that are directly involved on tourism development, both public and private (i.e., policy makers and tourism SMEs) must address the issue of offering high quality services. In order to provide a high quality services, tourism SMEs (which represents the whole tourism businesses in the sector) should innovate. Indeed, one of the most important reasons for innovation is service quality improvements and customer satisfaction (Pikkemaat, 2008) which in turn directly enhance the performance.

Although tourism in Albania is currently one of the sectors with a significant role on socio-economic development, it is still in an early stage of development and faces important challenges. Thus, property rights issues, high levels of informality, an underdeveloped infrastructure, seasonality and inadequately educated workforce are major concerns that clearly affect the daily operations of tourism SMEs and can make it difficult for them to continuously to innovate in terms of products and services. Given these specific features of the Albanian context, exploring the determinants of tourism SME performance takes on particular significance.

\section{Methodological approach}

\subsection{Data collection and sample}

WTTC (2018) shows that hotels, guesthouses, tourism agencies and restaurants significantly contribute to tourism development. As a result, hotels, restaurants and tourism agencies in Albanian's tourism will constitute the target group of this study. This target group will be stratified regarding the SMEs' criterion. As defined by the EU Commission (2005), SMEs are all those enterprises that have fewer than 250 employees. As a result, those who meet this criterion was part of the target group of this study.

Referring to the INSTAT (2018) within the tourism sector operate 1421 accommodation units, 1122 tourism agencies and 20488 food and beverage enterprises, constituting $14.4 \%$ of total enterprises that operate in Albania. A number of around 656 hotels, restaurants and tourism agencies (comprising $2.8 \%$ of the total population) was a reasonable target group of the study.

A questionnaire composed of 4 sections about owners and SMEs' general information, performance, innovativeness and innovation behavior, which was used for gathering the data with SMEs' senior managers or owners. The managers serve as key-informants because of their superior access to information about most aspects of a SMEs' activities (Sandvik \& Sandvik, 2003). We utilized self-reported data technique which is strongly supported in the literature (see e.g. Tajeddini \& Trueman, 2012; Hooley et al., 2000, Kirca et al., 2005). This study employed face-to-face interviews technique with the owner-managers of the SMEs, which has a very high response rate, roughly $95 \%$ (see e.g., Thornberry, 1987). Due to the time and costs associated with this method, we selected randomly 230 firms from the original 
list with the aim to achieve a reasonable sample size (see e.g. Hair et al., 2014). Using this method, we were able to conduct 215 face-to-face interviews, as 15 cases were unavailable and/or refused to participate, and thus achieve a response rate of 93.4\%. However, after addressing the issue of the amount and pattern of missing values within the data gathered, only 211 valid cases remained, representing our final sample. Such a sample size allows us to reduce sampling error, estimate the variability in the population, increase the confidence level and level of accuracy, and ultimately undertake both scale validation and refinement (see e.g. Hair et al., 2014).

\subsection{Respondents and SMEs profiles}

The majority of the responders on our target group were male $(69 \%)$ and the rest was female $(31 \%)$. The dominant youth decision makers due to the fact that responders' age was within the interval 18-39 years old. This is in line with the average age of the Albania population (37 years old) (INSTAT, 2017). Most respondents had completed Bachelor degree (65\%), and the rest Post-University (M.Sc.; PhD) (18\%), College (16\%) and Primary School $(1 \%)$. The majority $(60 \%)$ worked as a manager, as the owner $(33 \%)$, and both, manager and owner $(7 \%)$.

The major responders were from restaurants $38.8 \%$, followed by hotel industry $37.9 \%$, and tourism agencies $23.3 \%$. As regards to the number of employees, tourism SMEs had in average 16 employees. In addition, the average longevity of an SME was 9 years old. These figures confirmed that SMEs account for $100 \%$ of the sector enterprises, considering the number of employee criteria, and furthermore, that this sector has a short life span.

Table 1. Respondents and SMEs profiles $(\mathrm{N}=211)$

\begin{tabular}{lcc}
\hline Characteristics & Frequency & Percentage \\
\hline Gender & 66 & 31 \\
\hline Female & 145 & 69 \\
\hline Male & 73 & 35 \\
\hline Age & 85 & 40 \\
\hline $18-28$ & 41 & 19 \\
\hline $29-39$ & 9 & 4 \\
\hline $40-50$ & 3 & 1 \\
\hline $51-60$ & & 1 \\
\hline Over 60 & 2 & 16 \\
\hline Education & 33 & 65 \\
\hline Primary school & 138 & 18 \\
\hline College & 38 & 60 \\
\hline Bachelor & & 33 \\
\hline Post-Graduate $(M S c$, PhD) & 127 & 7 \\
\hline Role on SMEs hierarchy & 69 & \\
\hline Manager & 15 & 37.9 \\
\hline Owner & & 38.8 \\
\hline Owner and manager & 80 & 23.3 \\
\hline SMEs profile & 82 & Average \\
\hline Hotel & 49 & 9 \\
\hline Restaurant & 25 & 16 \\
\hline Tourism agency & 150 & \\
\hline Firm age & & \\
\hline Number of employees & 25 & \\
\hline
\end{tabular}




\subsection{Variables and measures}

The observed variables are based on the subjective approach. The justification for the subjective measure, as Foreman-Peck et al. (2006) argue, is the lack of the data that many SMEs are willing or obliged to put in the public domain. Additionally, previous researches have noted that objective measures correlate to objective measures (Sin et al., 2005; Tajeddini, 2010; Tajeddini \& Trueman, 2012).

All items that we used to operationalize the unobserved variables in this study are grounded from the existing literature. Performance measurement as the outcome variable will be operationalized in financial and non-financial terms. Thus, considering the financial measures (profitability) three items were based on Chen et al. (2009) study. In addition, considering the service-based nature of the tourism, it is reasonable to operationalize the performance in terms of customer loyalty/retention (see e.g. Chen et al., 2009; Wang et al., 2012; Tajeddini et al., 2013; Avlonitis et al., 2001; Grissemann et al., 2013). Therefore, we considered two items from Chen et al. (2009), one item from Wang et al. (2012), one item from Hooley et al. (2000) and Kirca et al. (2005). Innovativeness was measured by using seven items based on Hurley \& Hult (1998) and two items from Tsai \& Yang (2013). To measure the innovation behavior, we referred to the Johannessen et al. (2001) work by using seven items, and the author developed two other items during the discussion with the target group.

All the observed variables of the three unobserved variables (performance, innovativeness and innovation behavior) are rated using a five-point Likert scale with 1 being "strongly disagree" to 5 being "strongly agree.".

\subsection{Measurement model}

Within the framework of the social science studies, the most known statistical procedure for investigating relations between sets of observed and unobserved variables is factor analysis (Byrne, 2010). Mostly, factor analysis seeks to answer the question: does the conceptual model, with a relatively small number of factors, fit to the observed data?

Factor analysis contains two basic types; exploratory factor analysis (EFA) and confirmatory factor analysis (CFA). Both these types are explorative in their nature, aiming to investigate the structure of a set of observed variables that highly load onto factors of which they are indicators and exhibit small loadings on factors that are measured by differing sets of observed variables (Byrne, 2010).

Exploratory factor analysis is the most used technique in the social sciences (Field, 2009). Through EFA we examined basic descriptive analyses (Panayides \& So, 2005), such as standard deviation, explained variance, mean etc. Within the EFA, there are several methods to explore factors in our data such as Maximum Likelihood (ML), principal component analysis (PCA), principal factors analysis (principal axis factoring) and image covariance analysis (image factoring) etc., (Field, 2009). In addition, by using EFA, we are interested to validate the questionnaire, which means that we have to check the reliability of the constructs (Field, 2009). In our study, we used the Cronbach's alpha $(\alpha)$ measure to test for the reliability. Thus, a PCA method and reliability test was conducted.

In contrast to EFA, CFA is mostly used when the researcher has some prior knowledge of the underlying latent variable structure (Byrne, 2010). Thus, postulated relations between the observed measures and factors are based on previous knowledge of the theory and empirical research. Additionally, through the CFA it is determined the good fit of the hypothesized model to the data. 
Prior to hypothesis testing, exploratory factor analysis (EFA) and confirmatory factor analysis (CFA) were employed to evaluate the econometric and psychometric properties, ensure reliability (Kim \& Mueller, 1978), convergent validity (Fornell \& Larcker, 1981) and discriminant validity (Bagozzi \& Phillips, 1982; Joreskog, 1971; Gerbing \& Anderson, 1992). These procedures are implemented by using SPSS and AMOS software.

In the framework of the EFA procedure, a PCA method was conducted on 25 items, performance ( 7 items), innovativeness ( 8 items) and innovation behavior (10 items) measurements with orthogonal rotation (varimax) and eigenvalues with criteria of 1.0 (Kaiser, 1974). Four out of eight items of the performance construct, four out of eight items of innovativeness construct and six out of ten items of innovation behavior construct were deleted. These items were deleted for further analyses because during the data reduction (PCA) analysis, they were not respectively measuring the same common underlying dimension as they were supposed to measure and predicted in the previous literature. After deletion of those items, Cronbach's $\alpha$ values for performance (0.79), innovativeness $(0.72)$ and for innovation behavior (0.77), reveal the high reliability of the constructs. As the Table 1 shows, alpha coefficients of all three constructs (unobserved variables) exceed the value of 0.70 , as recommended by Nunnally (1978). As a result, the reliability of the measurements is achieved.

Table 2. Construct measurements

\begin{tabular}{|c|c|c|c|c|}
\hline & Mean & SD & FL & $\mathrm{EV}$ \\
\hline Performance $(\boldsymbol{\alpha}=\mathbf{0 . 7 9 3})$ (based on Chen et al., 2009) & & & & $14.6 \%$ \\
\hline Q. 11; We have achieved profit objectives & 3.63 & .959 & .898 & \\
\hline Q. 12; We have achieved sales objectives & 3.65 & .892 & .873 & \\
\hline Q. 10; We have been profitable & 4.13 & .643 & .719 & \\
\hline $\begin{array}{l}\text { Innovativeness ( } \boldsymbol{\alpha}=\mathbf{0 . 7 2} \text { ) (based on Hurley and Hult, 1998; } \\
\text { Tsai and Yang, 2013) }\end{array}$ & & & & $28 \%$ \\
\hline Q18; New ideas are quickly accepted in our company & 3.81 & .863 & .847 & \\
\hline $\begin{array}{l}\text { Q20; Our enterprise promotes the need for development } \\
\text { and utilization of new resources }\end{array}$ & 3.94 & .861 & .723 & \\
\hline Q17; Our enterprise is open to new ideas & 4.35 & .676 & .707 & \\
\hline $\begin{array}{l}\text { Q21; Innovation, based on research results, is readily } \\
\text { accepted in our organization }\end{array}$ & 3.46 & .940 & .632 & \\
\hline $\begin{array}{l}\text { Innovation Behavior }(\boldsymbol{\alpha}=\mathbf{0 . 7 0 6}) \text { (Based on Johannessen et } \\
\text { al., 2001) }\end{array}$ & & & & $16.7 \%$ \\
\hline $\begin{array}{l}\text { Q34; We continuously aim to create connections with other } \\
\text { stakeholders that provide to us innovative opportunity } \\
\text { (associations, other tourism enterprises such as hotel- } \\
\text { Tourism agency, etc.) }\end{array}$ & 3.98 & 1.064 & .721 & \\
\hline $\begin{array}{l}\text { Q31; We have implemented security systems in our } \\
\text { enterprise }\end{array}$ & 4.18 & 1.074 & .810 & \\
\hline $\begin{array}{l}\text { Q26; We have implemented Information and } \\
\text { communication technologies }\end{array}$ & 4.23 & .921 & .667 & \\
\hline $\begin{array}{l}\text { Q32; Our business provide entertainment, animation and } \\
\text { leisure activities }\end{array}$ & 3.84 & 1.186 & .664 & \\
\hline
\end{tabular}

Note: SD, standard deviation; FL, factor loadings; EV, explained variance.

The Kaiser-Meyer-Olkin measure verified the sampling adequacy for the analysis, $\mathrm{KMO}=0.72$, and all $\mathrm{KMO}$ values for individual items were $>0.65$, which is well above the acceptable limit of 0.5 (Kaiser, 1974). Bartlett's test of sphericity $\chi^{2}(15)=626.129, \mathrm{df}=55$, 
$\mathrm{p}<.001$, indicated that correlations between items were sufficiently large for PCA. An initial analysis was run to obtain eigenvalues. Three component had eigenvalues over Kaiser's criterion of 1 and explained $60 \%$ of the total variance, respectively $28 \%$ in innovativeness, $16.7 \%$ in innovation behavior and $14.6 \%$ in performance, all exceeding $10 \%$ (Falk \& Miller, 1992).

EFA served as a preliminary analysis of our data before we create the path diagram or the initial hypothesized model and to measure it through CFA. Thus, a CFA using covariance matrices and the maximum likelihood estimation procedure in AMOS 21.0.0 software were modeled for the scales.

In order to define if the hypothesized model fit to the data, it is crucial to consider the goodness-of-fit indices. Indeed, there are several indices of goodness-of-fit. However, we referred to the Hooper et al. (2008) suggestions to select the most important indices. Thus, they suggested the Chi-Square statistic $\left(\chi^{2}\right)$, its degree of freedom (DF) and p-value (P), CFI and RMSEA. The P-value of the $\chi^{2}$, it is suggested to be bigger than 0.05 (Hooper et al., 2008), CMIN/DF that fall into the interval 1-2 (Tabachnick et al., 2006). However, both these indices are considered subjective. The comparative fit index (CFI) (Bentler, 1990), assumes that all latent variables are uncorrelated. Values for this indices range between 0.0 and 1.0 with values greater than 0.95 indicating a good-fit. The last and probably most important indicator for the fitting model is RMSEA (Steiger \& Lind, 1980). By analyzing the RMSEA, we answer to the question "How well would the model, with unknown but optimally chosen parameter values, fit the population covariance matrix if it were available?" (Browne \& Cudeck, 1993, pp. 137-138). Values of RMSEA ranging from 0.08 to 0.10 indicate mediocre fit, those greater than 0.10 indicate poor fit, and RMSEA values less than 0.05 indicate good fit (Byrne, 2010).

As a result, considering these indices, the re-specified or the alternative model indicate a very good fit to the data $(\chi 2=58.769 ; \mathrm{df}=40 ; \mathrm{p}=0.028 ; \mathrm{CMIN} / \mathrm{DF}=1.46 ; \mathrm{CFI}=0.968$, RMSEA=0.047). Since we cannot further improve the model through modification indices (MI), we can conclude that this alternative model is the final hypothesized model that best fit to the data.

\subsection{Convergent validity, discriminant validity and common method variation}

SEM methodology considers very important convergent validity (Fornell \& Larcker, 1981) and discriminant validity (Bagozzi \& Phillips, 1982; Joreskog, 1971; Gerbing \& Anderson, 1992). These two tests are significant in order to have credible an accurate generalization study results.

Convergent validity measures the correlation between observed variables used to measure the same construct. Convergent validity is achieved when each indicator's estimated pattern coefficient on its posited underlying construct factor, is significant (Anderson and Gerbing, 1988). In addition, Jöreskog \& Sörbom (1996) suggested that the factor loadings $>0.45$ are accepted. As shown in Figure 2, all items loadings ranging from 0.51 to 0.91 , exceeding the threshold 0.45 , are significant at the 0.001 level, indicating convergent validity.

Apart from the significance of the factor loadings, to define the convergent validity, we considered the composite reliability (CR) (Fornell \& Larcker, 1981). Thus, CR was calculated for three constructs using the procedures suggested by Fornell \& Larcker (1981). The CR for performance is 0.81 , innovativeness 0.75 and for innovation behavior 0.72 , all exceeding 0.6 threshold, suggested by Bagozzi \& Yi (1988). Finally, we concluded that the convergent validity is achieved.

Through discriminant validity, we investigate if an observed variable does not correlate with another observed variable from which it is supposed to be different (between 
two constructs). We followed the Joreskog (1971) and Bagozzi \& Phillips (1982) procedures for the discriminant validity. This procedure considers the difference between chi-squares $(\chi 2)$ values obtained from the constrained correlation (fixed to 1) and unconstrained correlation (freely estimated) between factors (Joreskog, 1971). In addition, this test was performed for one pair of constructs at a time, rather than as a simultaneous test to the model as a whole (Anderson \& Gerbing, 1988). In this vein, as Bagozzi \& Phillips (1982) stated, "A significantly lower $\chi^{2}$ value for the model in which the trait correlations are not constrained to unity would indicate that the traits are not perfectly correlated and that discriminant validity is achieved" (p. 476). As shown in Table 2, all pair models with constrained correlations performed a significantly higher chi-square compared to the unconstrained pair's models. Thus, all combinations resulted in higher critical value $(\Delta \chi 2>3.84$ at the $p<0.0001$ significance level), indicating that the factors are not perfectly correlated and that discriminant validity is achieved (Anderson \& Gerbing, 1988).

Table 3. Correlations fixed to 1 and freely estimated between pair's constructs

\begin{tabular}{lll}
\hline Pairs & Correlation fixed to 1 & Correlation estimated freely \\
\hline Perfo $\Leftrightarrow$ Inness & Chi-square $=159.032 ; \mathrm{P}=0.000$ & Chi-square $=11.946 ; \mathrm{P}=0.450$ \\
\hline Perfo $\Leftrightarrow$ Innbeh & Chi-square $=172.117 ; \mathrm{P}=0.000$ & Chi-square $=25.744 ; \mathrm{P}=0.018$ \\
\hline Inness $\Leftrightarrow$ Innbeh & Chi-square $=153.333 ; \mathrm{P}=0.000$ & Chi-square $=26.912 ; \mathrm{P}=0.081$ \\
\hline
\end{tabular}

\section{Results of hypothesis testing}

The study applies structural equation modeling methodology to establish causal relationships between factors and to test the hypotheses. This statistical methodology translates the theoretical constructions into a mathematical model (Jöreskog \& Sörbom, 1996) and provides estimation and evaluation of the model empirically. The maximum-likelihoodestimation is used to examine the hypothesized relationships among innovativeness, innovation behavior and performance (see Figure 1).

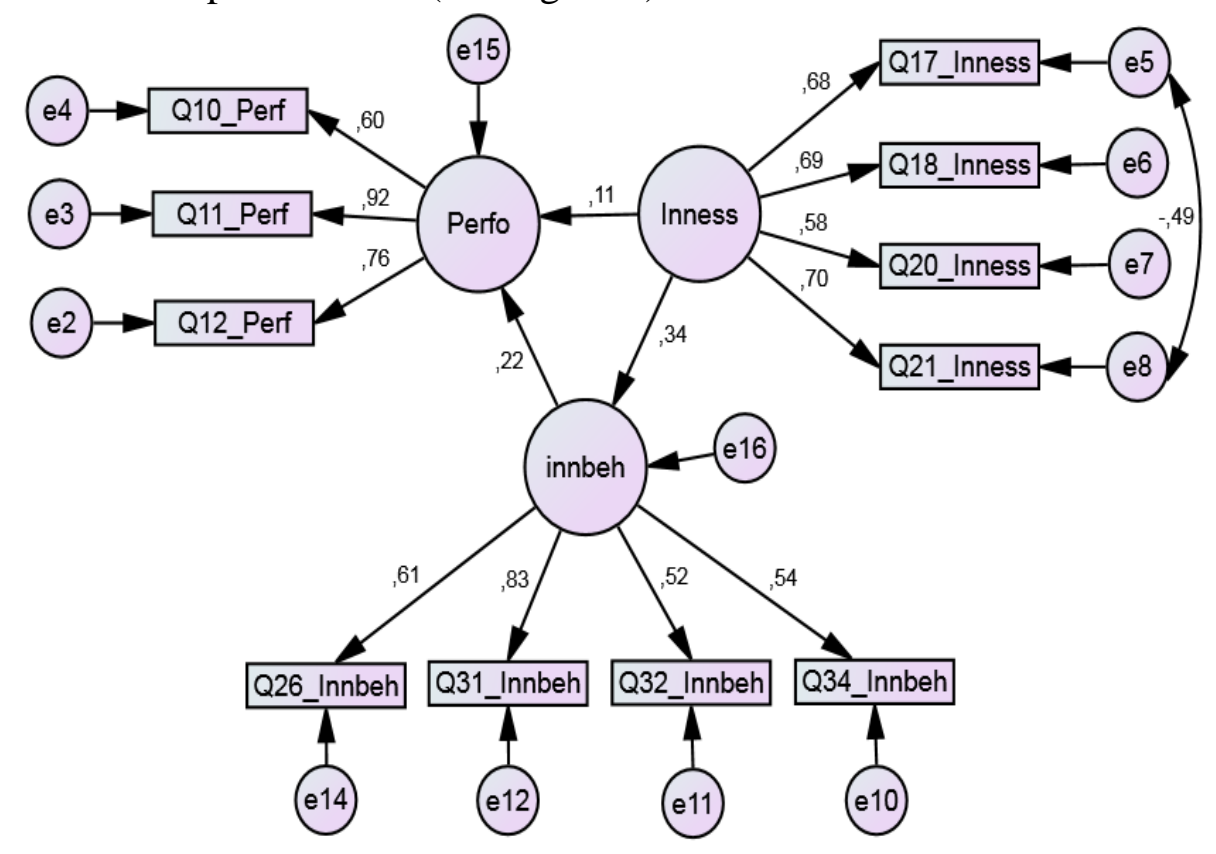

Figure 1. The hypothesized structural equation model 
H1 considers the effects of innovativeness on performance. In contrary to our expectation, innovativeness is not significantly effecting the performance (Coefficient $=0.093$; $\mathrm{t}$-value $=1.269 ; p>0.05$ ). Thus, due to the $\mathrm{p}$-value bigger then 0.05 , and its $\mathrm{t}$-value less than 1.96, this hypothesis is rejected (see Table 3), which in turn indicate that if SMEs are open to new idea and these new ideas are quickly accepted, their performance is not likely to enhance.

The results of $\mathrm{H} 2$ reported in the Table 3 indicate that innovativeness has a significant positive effect on innovation behavior (Coefficient $=0.426$; $t$-value $=3.388$; $p<0.001$ ). In other words if SMEs promotes the need for development and utilization of new resources, open to new ideas, readily accepted research based results, they are likely to practically implement innovation such as information and communication technologies.

The H3 investigate the effect of innovation behavior on performance. Results show that innovation behavior has a significant positive effect on performance $($ Coefficient $=0.150$; $\mathrm{t}$-value $=2.323 ; \mathrm{p}<0.05)$. This result indicate that the more SMEs practically implement innovation the more they will likely achieve profit and sales objectives.

Table 4. Hypotheses and standardized structural estimates of the model

\begin{tabular}{lcccc}
\hline \multicolumn{1}{c}{ Path } & & Coefficient & t-value & $\mathrm{P}$ \\
\hline Inness $\rightarrow$ Perfo & $\mathrm{H} 1$ & 0.093 & $1.269 \mathrm{~ns}$ & 0.204 \\
\hline Inness $\rightarrow$ Innbeh & $\mathrm{H} 2$ & 0.426 & $3.388^{* *}$ & $* * *$ \\
\hline Innbeh $\rightarrow$ Perfo & $\mathrm{H} 3$ & 0.150 & $2.323^{* *}$ & 0.020 \\
\hline
\end{tabular}

Goodness-of-fit statistics: $\chi^{2}=58.769 ; \mathrm{df}=40 ; \mathrm{p}=0.028 ; \mathrm{CMIN} / \mathrm{DF}=1.46 ; \mathrm{CFI}=0.96, \mathrm{RMSEA}=0.047$ ). Note: $* * * \mathrm{P}<0.001$ (two-tailed test); $* * \mathrm{P}<0.05$ (two-tailed test); ns, not supported.

To test the mediation effects proposed in $\mathrm{H} 4$, we followed the recommendations of Preacher \& Hayes (2008) and conducted a detailed multiple mediation analysis. The suggested bootstrap method is employed.

Table 5. Results of the mediator test

\begin{tabular}{clll}
\hline $\begin{array}{c}\text { Hypothesis } \\
\text { (Indirect effects) }\end{array}$ & $\begin{array}{l}\text { Direct } \beta \text { with } \\
\text { the mediator }\end{array}$ & Indirect $\beta$ & Mediation type \\
\hline Inness $\rightarrow$ Innbeh $\rightarrow$ Perfo (H4) & $0.111 \mathrm{~ns}$ & $0.076^{* *}$ & $\begin{array}{l}\text { Indirect only } \\
\text { mediation }\end{array}$ \\
\hline
\end{tabular}

Note: $* * \mathrm{P}<0.05$ (Bootstrap, two-tailed significance); ns, not significant.

Through the $\mathrm{H} 4$ we examined the indirect effect of innovativeness on performance mediated by innovation behavior. Indeed, as Zhao et al. (2010) defined, since that direct effect of innovativeness on performance, is not significant (Coefficient $=0.111, p=0.161>0.05$ ) and its indirect effects through mediation role of innovation behavior results significant (Coefficient $=0.076, \mathrm{p}=0.003<0.05$ ), indicate that this mediation type is an indirect only mediation. Finally, as shown in Table 4, results confirm that innovation behavior plays a significant role as a mediator on the innovativeness-SMEs performance relationship. 


\section{Discussion and conclusion}

\subsection{Theoretical and practical implications}

This study examines the effects of innovativeness and innovation behavior on tourism SMEs' performance. Specifically, the goal of this paper was to investigate the extent to which innovativeness and innovation behavior affects performance.

Literature that measure innovation in terms of innovativeness (see e.g. Hult et al., 2004; Grissemann et al., 2013; Tajeddini, 2010; Tajeddini \& Trueman, 2012) and innovation behavior (see e.g. Orfila-Sintes \& Mattsson, 2009; Grissemann et al., 2013) has only begun to scratch the surface. Therefore, operationalization of the vague term of innovation is a contribution to the literature.

Results of this study indicate that there is a significant effect of innovativeness on innovation behavior. This is in line with the findings of Grissemann et al. (2013), AtuaheneGima (1996) and De Jong et al. (2003) who concluded that the more employees and managers are open toward the new idea and the change, the more the innovation will take place into the SME. The representatives (managers and/or owners) of Albanian tourism SMEs believe that if their staff is opened and has a positive attitude toward the new idea and the change, the implemented innovation in practice within SME will increase. In addition, it is suggested that managers identify and value new ideas to encourage employees to "think out of the box" and share their creativity (Tajeddini, 2010), which in turn will facilitate and encourages practical implementation of innovation. This result is a practical implication in terms of SMEs management, suggesting that if SMEs managers/owners will be open towards innovation, accepting new ideas, encouraging new resources for innovation and transforming the study's results into the innovation, the more innovation into the SMEs will take place. Thus, innovativeness is an attitude for allowing the business to achieve sustainable competitive advantage. In this line, SMEs managers/owners must consider innovativeness as an integral part of their strategy. However, to facilitate attitudinal dimension of innovation, SMEs managers have to consider the values and beliefs of employees, as well.

In contrast to our initial thoughts, innovativeness does not significantly influence performance. This result is in contrast to the conclusions of Hult et al. (2004), Tsai \& Yang (2013), Tajeddini (2010), and Tajeddini \& Trueman (2012). By referring to the qualitative data, along the open interviews with SMEs managers, it resulted that rejection of this hypothesis it could be related to the reason that Albanian tourism sector has a short life-span and is not well organized, which in turn reflects, lack of necessary experience to think about creativity and its importance for the firm success. In addition, SMEs' managers along with their daily management, often deal with vulnerable issues (lack of electricity, lack of water supply, lack of necessary human capacity etc.) which hinder their focus on creativity. Furthermore, through qualitative data analysis, it resulted that managers used the attitudinal dimension of innovation and innovation behavior interchangeable. In addition, they stated that it is impossible that values and beliefs on innovation may affect performance.

Regarding innovation behavior, results indicate that is significantly affecting performance. This conclusion is in line with the findings of Grissemann et al. (2013), OrfilaSintes \& Matsson (2009) and Rosendbuch et al. (2011). Tourism as a service industry is vulnerable to changes, and as a result, innovation seems inevitable (Tajeddini, 2010). In order to achieve sustainable competitive advantages, tourism SMEs need to be adjusted to this dynamic environment, wherein innovation plays a key role in this dimension. The results of the study indicate that the more tourism's SMEs innovate in terms of ICT, cooperation (associations, networks etc.), the more their financial performance will increase. In this vein, managers are advised to implement the ICT, to innovate in terms of providing animation and 
leisure, and to cooperate through associations or networks in order to achieve their profits and sales goals.

While innovativeness does not affect SMEs performance directly, its indirect effects through the mediation role of innovation behavior are significant. This result is in line with Grissemann et al. (2013) study who found a positive link between innovativeness and business performance, wherein this link was mediated by innovation behavior. Consequently, SMEs managers or owners should consider both, innovativeness and innovation behavior and their interplay, as important factors that will increase their business performance.

Since we collected the data across Albania, which is a developing country, the results may be generalized and applied for other developing countries. This study argues that in contrast to the developed countries (see e.g., Tajeddini, 2010; Tajeddini \& Trueman, 2012) in developing countries managers do not consider innovativeness as an important factor that affects financial performance. Nevertheless, further researches are advised to be undertaken.

Another important contribution of this study is that the target group was not only on the hotel industry, which is the most used in previous researches about innovation (see e.g. Grissemann et al., 2013; Tajeddini, 2010; Tajeddini \& Trueman, 2012; Orfila-Sintes \& Mattsson, 2009. In this regard, the applicability of our results is not limited to only one industry (hotels, restaurants etc.), but to the tourism sector as a whole.

\section{Limitations of the study and future lines of research}

While our study is a significant contributor in terms of theory and practice, on the other hand, it should be acknowledged that there are also limitations that should be considered. Firstly, within our study, we have used the cross-sectional data to empirically investigate the proposed hypothesized models. This imposes us to posit that our conclusions are related and valid at one point in time (see e.g. Tajeddini et al., 2013). In this regard, future longitudinal studies could cross-validate the current findings and provide additional support regarding the causality of the above hypothesis proposed. Additionally, data analyzed (observed variables) in our study are based on subjective evaluation (five Point Likert-scales) (e.g., Greenley \& Foxall, 1996). The subjective nature of this data imposes us to posit that the conclusions may be interpreted with caution. Secondly, even though our study intended to have more comprehensive results within the tourism sector, and not considering the differences between SMEs (tourism agencies, restaurant and hotels) in terms of innovativeness and innovation behavior, would be a reason to prejudge the results. Thus, future researches that consider the same conceptual models within different industries such as the hotel industry, tourism agencies industry, restaurants industry, would be an important contribution. Thirdly, even though this study aimed to select the most significant factors (innovativeness, innovation behavior) that affect SMEs performance, future efforts in searching for more significant factor affecting SMEs performance, are advised. This came as a consequence of the fact that performance, is a multidisciplinary concept, and consequently, is determined by a large and complex factors.

\section{References}

Agarwal, S., Krishna Erramilli, M., \& Dev, C. S. (2003). Market orientation and performance in service firms: role of innovation. Journal of services marketing, 17(1), 68-82.

Anderson, J., \&. Gerbing, D. (1988). Structural equation modeling in practice: A review and recommended two-step approach. Psychological Bulletin, 103, 411-423. 
Atuahene-Gima, K. (1996). Marketing orientation and innovation. Journal of Business Research, 35, 93-103.

Avlonitis, G.J., Papastathopoulou, P.G., \& Gounaris, S.P. (2001). An empirically-based typology of product innovativeness for new financial services: success and failure scenarios. Journal of Product Innovation Management, 18, 324-342.

Bagozzi, R. P., \& Yi, Y. (1988). On the evaluation of structural equation models. Journal of the Academy of Marketing Science, 16(1), 74-94.

Bagozzi, R. P., \& Phillips, L. W. (1982). Representing and testing organizational theories: A holistic construal. Administrative science quarterly, 459-489.

Baregheh, A, Rowle, J, \& Sambrook, S. (2009). Towards a multidisciplinary definition of innovation. Management Decision, 47(8), 1323-1339.

Baum, T. (1995). Managing human resources in the european tourism and hospitality industry: a strategic approach. London: Chapman and Hall.

Bentler, P. M. (1990). Comparative fit indexes in structural models. Psychological bulletin, 107(2), 238-246.

Birley, S., \& Westhead, P. (1990). Growth and performance contrasts between 'types' of small firms. Strategic Management Journal, 11(7), 535-557.

Byrne, B. (2010). Structural Equation Modeling with AMOS: Basic Concepts, Applications, and Programming. 2 ed. New York: Routledge.

Brännback, M. (1999). The Concept of Customer-Orientation and its Implications for Competence Development, s.l.: Innomarket Technical Reports.

Browne, M. W., \& Cudeck, R. (1993). Alternative ways of assessing model fit. In K. A. Bollen \& J. S. Long (Eds.). Testing structural equation models (pp. 136-162). Newbury Park, CA: Sage.

Chan, A., Go, F.M., \& Pine, R. (1998). Service innovation in Hong Kong. Attitudes and practice. The Service Industries Journal, 18(2), 112-124.

Chen, J. S., Tsou, H. T., \& Huang, A. Y. H. (2009). Service delivery innovation: Antecedents and impact on firm performance. Journal of Service Research, 12(1), 36-55.

Commission. (2005). The new SME definition: Brussels: European Commission.

Cronbach, L.J. (1951). Coefficient alpha and the internal structure of tests. Psychometrika, 16, 297-334.

Daft, R.L. (1978). A dual core model of organizational innovation. Academy of Management Journal, 21, 193-210.

Damanpour, F., \& Wischnevsky J.D. (2006). Research on organizational innovation: distinguishing innovation-generating from innovation-adopting organizations. Journal of Engineering and Technology Management, 23, 269-291.

De Jong, J.P.J., W. Dolfsma, A. Bruins \& Meijaard, J. (2003). Innovation in service firms explored: what, how and why? Strategic study. EIM Business \& Policy Research, 1-73.

DeCarolis, D.M., \& Deeds, D.L. (1999). The impact of stocks and flows of organizational knowledge on firm performance: an empirical investigation of the biotechnology industry. Strategic Management Journal, 20(10), 953-968.

Domi, S., Keco, R., Musabelliu, B., \& Kapaj, I. (2018). A review of factors affecting SMEs performance: An Albanian rural tourism perspective. Albanian journal of Agricultural Science, Special edition-ICOALS, 713-718. 
Falk, R., \& Miller, N. (1992). A Primer for Soft Modelling. Akron: University of Akron Press.

Field, A. (2009). Discovering statistics using spss. 3 ed. London: SAGE Publications Ltd.

Fitzgerald, L., \& Moon, P. (1996). Performance Measurement in Service Industries: Making it Work. London: CIMA.

Foreman-Peck, Makepeace, G., \& Morgan, B. (2006). Growth and Profitability of Small and Medium-sized Enterprises: Some Welsh Evidence. Regional Studies, 40(4), 307-319.

Fornell, C., \& Lacker, D. (1981). Evaluating structural equation models with unobservable variables and measurement error. Journal of Marketing Research, 18, 39-50.

Gerbing, D.W., \& Anderson, J.C. (1992). Monte Carlo evaluations of goodness of fit indices for structural equation models. Sociological Methods and Research, 21(2), 132-160.

Gilmore, J.P., \& Pine, J. (2002). Differentiating hospitality operations via experiences: why selling services is not enough. The Cornell Hotel and Restaurant Administration Quarterly, 43, 87-96.

Grissemann, U., Plank, A., Brunner-Sperdin, A. (2013). Enhancing business performance of hotels: The role of innovation and customer orientation. International Journal of Hospitality Management, 33, 347-356.

Hair, J.F., Black, W.C., Babin, B.J., Anderson, R.E. (2014) Multivariate Data Analysis (7 $7^{\text {th }}$ edition). Essex: Pearson Education.

Hall, C.M. (2009). Innovation and tourism policy in Australia and New Zealand: never the twain shall meet? Journal of Policy Research in Tourism, Leisure and Events, 1(1), 218.

Hall, D. (2000). Tourism as sustainable development? The Albanian experience of 'transition'. International Journal of Tourism Research, 2, 31-46.

Heunks, F. (1998). Innovation, creativity and success. Small Business Economics, 10(3), 263272.

Hjalager, A.M., \& Flagestad, A. (2012). Innovations in well-being tourism in the Nordic countries. Current Issues in Tourism, 15(8), 725-740.

Hjalager, M. (2010). A review of innovation research in tourism. Tourism Management, 31, $1-12$.

Hooley, G., Cox, T., Fahy, J., Shipley, D., Beracs, J., Fonfara, K., \& Snoj, B. (2000). Market Orientation in the Transition Economies of Central Europe: Tests of the Narver and Slater Market Orientation Scales. Journal of Business Research, 50, 273-285.

Hooper, D., Coughlan, J., \& Mullen, M. (2008). Structural Equation Modelling: Guidelines for Determining Model Fit. Electronic Journal of Business Research Methods, 6, 53-60.

Hult, G., Hurley, R., \& Knight, G. (2004). Innovativeness: its antecedents and impact on business performance. Industrial Marketing Management, 33, 429-438.

Hurley, R., \& Hult, G. (1998). Innovation, market orientation, and organizational learning: An integration and empirical examination. Journal of Marketing, 62 (3), 42-54.

INSTAT (2017). Vjetari statistikor. Tirana: INSTAT.

INSTAT (2018). Regjistri i bizneseve, Tirana: INSTAT.

Ivanová, E., \& Čepel, M. (2018). The impact of innovation performance on the competitiveness of the Visegrad 4 countries. Journal of Competitiveness, 10(1), 54-72. 
Johannessen, J.A., Olsen, B., \& Lumpkin, G.T. (2001). Innovation as newness: what is new, how new, and new to whom? European Journal of Innovation Management, 4, 20-31.

Jones, E., \& Haven, C. (2005). Tourism SMEs, Service Quality and Destination Competitiveness. London: CABI.

Joreskog, K. (1971). Statistical Analysis of Sets of Congeneric Tests. Psychometrika, 32, 443482.

Jöreskog, K.G. \& Sörbom, D. (1996a). LISREL 8: User's reference guide. Chicago: Scientific Software International.

Kaiser, H.F. (1974). An index of factorial simplicity. Psychometrika, 39, 31-36.

Kim, J.O., \& Mueller. C.W, (1978). Factor Analysis: Statistical Methods and Practical Issues. Newbury Park CA: Sage Publications.

Kirca, A.H., Jayachandran, S., \& Bearden, W.O. (2005). Market orientation: a meta-analytic review and assessment of its antecedents and impact on performance. Journal of Marketing, 69(2), 24-41.

Kleysen, R.F., \& Street, C.T, (2001). Toward a multi-dimensional measure of individual innovative behavior. Journal of Intellectual Capital, 2(3), 284-296.

Lee, C., Hallak, R., \& Sardeshmukh, S. R. (2016). Innovation, entrepreneurship, and restaurant performance: A higher-order structural model. Tourism Management, 53, 215-228.

Li, H., Atuahene-Gima, K. (2001). Product innovation strategy and the performance of new technology ventures in China. Academy of Management Journal, 44(6), 1123-1134.

Matsuo, M. (2006). Customer orientation, conflict, and innovativeness in Japanese sales departments. Journal of Business Research, 59(2), 242-250.

Mok, C., \& Armstrong, W. R. (1998). Expectations for hotel service quality: Do they differ from culture to culture? Journal of Vacation Marketing, 4(4), 381-391.

MTM (2018). Strategjia kombëtare për zhvillimin e qëndrueshëm të turizmit 2018-2022 (Draft). Tirana: Ministria e Turizmit dhe Mjedisit.

Noble, CH., Sinha, R.K, \& Kumar, A. (2002). Market Orientation and Alternative Strategic Orientations: A Longitudinal Assessment of Performance Implications. Journal of Marketing, 66, 25-39.

Nunnally, J.C. (1978). Psychometric theory... s.l.: McGraw-Hill Book Company.

OECD (2005). The measurement of scientific and technological activities. Paris: European Commission EUROSTAT.

Orfila-Sintes, F., \& Mattsson, J. (2009). Innovation behavior in the hotel industry. Omega, 37(2), 380-394.

Orfila-Sintes, F., Crespi-Cladera, R., \& Martinez-Ros, E. (2005). Innovation activity in the hotel industry: evidence from Balearic Islands. Tourism Management, 26(6), 851-865.

Ottenbacher, M., \& Gnoth, J. (2005). How to develop successful hospitality innovation. The Cornell Hotel and Restaurant Administration Quarterly, 46(2), 205-222.

Ottenbacher, M., Gnoth, J., \& Jones, P. (2006). Identifying determinants of success in development of new high-contact services - insights from the hospitality industry. International Journal of Service Industry Management, 17, 344-363. 
Panayides, P. M., \& So, M. (2005). Logistics service provider-client relationships. Transportation Research Part E: Logistics and Transportation Review, 41(3), 179-200.

Pikkemaat, B. (2008). Innovation in small and medium-sized tourism enterprises in Tyrol, Austria. The International Journal of Entrepreneurship and Innovation, 9(3), 187-197.

Pine, R., (1992). Technology transfer in the hotel industry. International Journal of Hospitality Management, 11(1), 3-22.

Preacher, K.J., \& Hayes, A. (2008). A symptotic and resampling strategies for assessing and comparing indirect effects in multiple mediator models. Behavior Research Methods, 40(3), 879-891.

Rajnoha, R., \& Lorincová, S. (2015). Strategic Management of Business Performance Based on Innovations and Information Support in Specific Conditions of Slovakia. Journal of Competitiveness, 7(1), 3-21.

Rauch, A., \&. Frese, M. (2000). Psychological approaches to entrepreneurial success: a general model and an overview of findings. In: C. L. R. I. T. Cooper, ed. International review of industrial and organisational psychology. Chichester: Wiley, p. 101-142.

Rodgers, S. (2007). Innovation in food service technology and its strategic role. International Journal of Hospitality Management, 26, 899-912.

Rosenbusch, N., Rauch, A., Bausch, A. (2013). The mediating role of entrepreneurial orientation in the task-environment-performance relationship: A meta-analysis of 30 years of research. Journal of Management, 39, 633-659.

Sandvik, L., \& Sandvik, K. (2003). The impact of market orientation on product innovativeness and business performance. Journal of Product Innovation Management 20(4), 355-376.

Sandvik, I.L., Duhan, D.F., \& Sandvik, K. (2014). Innovativeness and profitability. An empirical investigation in the Norwegian hotel industry. Cornell Hospitality Quarterly, 55(2), 165-185.

Steiger J.H., (1980). Statistically based tests for the number of factors. The annual meeting of the Psychometric Society., Iowa. USA.

Storey, C.E., \& Easingwood, C.J. (1998). The augmented service offering: a conceptualization and study of its impact on new service success. Journal of Product Innovation Management, 15(4), 335-351.

Tabachnick, B.G., Fidell, L.S., \& Ullman, JB (2006). Using Multivariate Statistics. 5 ed. New York: Pearson Education.

Tajeddini, K. (2010). Effect of customer orientation and entrepreneurial orientation on innovativeness: evidence from the hotel industry in Switzerland. Tourism Management, $31,221-231$.

Tajeddini, K., \& Trueman, M. (2008). Effect of customer orientation and innovativeness on business performance: a study of small-sized service retailers. International Journal of Entrepreneurship and Small Business, 6(2), 280-295.

Tajeddini, K., \& Trueman, M. (2012). Managing Swiss Hospitality: How cultural antecedents of innovation and customer-oriented value systems can influence performance in the hotel industry. International Journal of Hospitality Management, 31, 1119-1129.

Tajeddini, K., Elg, U., \& Trueman, M. (2013). Efficiency and effectiveness of small retailers: The role of customer and entrepreneurial orientation. Journal of Retailing and Consumer Services, 20, 453-462. 
Terziovski, M. (2010). Innovation practice and its performance implications in small and medium enterprises (SMEs) in the manufacturing sector: A resource-based view. Strategic Management Journal, 31, 892-902.

Thornberry, O.T. (1987). An Experimental Comparison of Telephone and Personal Health Interview Surveys, Hyattsville: US Department of Health and Human Services, Public Health Service, National Center for Health Statistics.

Tsai, K.H., \& Yang, Sh.Y. (2013). Firm innovativeness and business performance: The joint moderating effects of market turbulence and competition. Industrial Marketing Management, 42, 1279-1294.

Van de Ven, A. (1986). Central problems in the management of innovation. Management Science, 32(5), 590-607.

Vermeulen, P.A.M., \& De Jong, J.P.J. (2005). Identifying key determinants for new product introductions and firm performance in small service firms. Service Industry Journal, 25(5), 625-640.

Wang, H., Chen, Y., Chen, C. (2012). Total quality management, market orientation and hotel performance: the moderating effects of external environmental factors. International Journal of Hospitality Management, 31(1), 119-129.

WEF (2015). The Travel \& Tourism Competitiveness Report 2015. Geneva: World Economic Forum.

World Bank (2019). International tourism, number of arrivals. Retrieved from https://data.worldbank.org/indicator/ST.INT.ARVL?end=2017\&locations=AL-AT-MEIT-MK-RS-GR\&start=2007\&view=chart\&year_low_desc=true. Date 29.4.2019.

WTTC (2018). Travel and tourism economic impact: Albania. London: World Travel and Tourism Council.

Zaltman, G., Duncan, R., \& Holbek, J. (1973). Innovations and organizations. New York: Wiley \& Sons. 